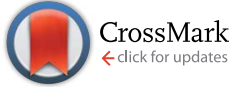

Cite this: J. Mater. Chem. A, 2016, 4, 10601

Received 28th April 2016

Accepted 9th June 2016

DOI: $10.1039 / c 6 t a 03552 c$

www.rsc.org/MaterialsA

\section{A high temperature reduction cleaning (HTRC) process: a novel method for conductivity recovery of yttrium-doped barium zirconate electrolytes $\dagger$}

\author{
Donglin Han, ${ }^{* a}$ Junji lihara, ${ }^{\text {b }}$ Shigeaki Uemura, ${ }^{b}$ Kenji Kazumi, ${ }^{\text {C Chihiro Hiraiwa, }}$ \\ Masatoshi Majimab and Tetsuya Uda*a
}

\begin{abstract}
Proton conducting $\mathrm{Y}$-doped $\mathrm{BaZrO}_{3}(\mathrm{BZY})$ and nickel oxide (NiO) are currently the most promising electrolyte and anode catalyst for protonic ceramic fuel cells, respectively. However, during the co-sintering process to fabricate the fuel cells, Ni cations diffuse from the anode into the lattice of the BZY electrolyte, resulting in significant degradation of the electrolyte conductivity and fuel cell performance. With the aim to solve such a problem, in this work, we report a novel method, named as high temperature reduction cleaning (HTRC) process, which is composed of several sequential heattreatments in controlled atmospheres. The most interesting point is that after heat-treating the $\mathrm{NiO}$-contaminated $\mathrm{BZY}$ at $1400{ }^{\circ} \mathrm{C}$ in a Ti-deoxidized $\mathrm{Ar}$ atmosphere for $100 \mathrm{~h}$, Ni cations were observed to be expulsed from the BZY lattice and segregated at the grain boundary as Ni metal particles. And the conductivity of the BZY electrolyte was recovered. However, delamination along the grain boundary of the BZY electrolyte was introduced when the segregated Ni metal particles were oxidized to $\mathrm{NiO}$ particles in an oxygen atmosphere. And a series of sequential heat-treatments were designed to solve such a problem.
\end{abstract}

\section{Introduction}

Because of potential application as efficient power generation devices, protonic ceramic fuel cells (PCFCs) operating in the intermediate temperature range $\left(450-700{ }^{\circ} \mathrm{C}\right)$ are receiving increasing attention. Y-doped $\mathrm{BaZrO}_{3}$ (BZY), which exhibits both high proton conductivity ${ }^{\mathbf{1 - 5}}$ and excellent chemical stability, ${ }^{6,7}$ is regarded as the most promising electrolyte for PCFCs. Nickel (Ni) and electronically conducting oxides (such as $\mathrm{La}_{1-x} \mathrm{Sr}_{x} \mathrm{Co}_{1-y} \mathrm{Fe}_{y} \mathrm{O}_{3-\delta}$ (LSCF)) are employed as the anode and cathode, respectively. Such a combination of materials leads to quite exceptional results. For example, Shafi et al. ${ }^{8}$ reported a $\mathrm{BaZr}_{0.76} \mathrm{Y}_{0.2} \mathrm{Ni}_{0.04} \mathrm{O}_{3-\delta}$ electrolyte-based fuel cell with a peak power density of $240 \mathrm{~mW} \mathrm{~cm} \mathrm{~cm}^{-2}$ at $600{ }^{\circ} \mathrm{C}$. A recent study by Duan et al. ${ }^{9}$ demonstrates a peak power density of 318 $\mathrm{mW} \mathrm{cm}{ }^{-2}$ at $600{ }^{\circ} \mathrm{C}$ for a cell with the $\mathrm{BaZr}_{0.8} \mathrm{Y}_{0.2} \mathrm{O}_{3-\delta}$ (BZY20) electrolyte. Nevertheless, it has been realized recently that special attention needs to be focused on the interaction between BZY and nickel oxide (NiO). ${ }^{10-14}$ The supporting anode is made from a mixture of $\mathrm{NiO}$ and the electrolyte material. After

${ }^{a}$ Department of Materials Science and Engineering, Kyoto University, Yoshida Honmachi, Sakyo-ku, Kyoto 606-8501, Japan.E-mail: uda_lab@aqua.mtl.kyoto-u.ac. jp; han.donglin.8n@kyoto-u.ac.jp; Fax: +81-75-753-5284; Tel: +81-75-753-5445

${ }^{b}$ Sumitomo Electric Industries, Ltd., 1-1-1, Koyakita, Itami-shi, Hyogo 664-0016, Japan $\uparrow$ Electronic supplementary information (ESI) available. See DOI: $10.1039 /$ c6ta03552c a thin BZY20 electrolyte layer is placed on the anode, the cell is subjected to a co-sintering process $\left(1400-1600{ }^{\circ} \mathrm{C}\right)$ for bi-layer fabrication. However, as shown in Table 1, the BZY20 thin electrolyte prepared by such a method shows a significant degradation in conductivity $\left(<2.7 \times 10^{-3} \mathrm{~S} \mathrm{~cm}^{-1}\right.$ at $\left.600{ }^{\circ} \mathrm{C}\right)$, greatly lower than the expected value of BZY20 $\left(>10^{-2} \mathrm{~S} \mathrm{~cm}^{-1}\right.$ at $\left.600^{\circ} \mathrm{C}\right) .{ }^{1,2,5}$ The predominant reason is due to the diffusion of $\mathrm{Ni}$ cations from the anode into the electrolyte layer by occupying an interstitial position of $(1 / 2,0,0)$ in the BZY crystal lattice during the co-sintering process. ${ }^{\mathbf{1 4 , 2 5}}$ Furthermore, nickel cations in the BZY electrolyte improves the sinterability; thus, 1 to $2 \mathrm{wt} \% \mathrm{NiO}$ is often added deliberately to the electrolyte., ${ }^{\mathbf{9}, 2,26-28}$ Undoubtedly, the performance of fuel cells will be greatly improved, if the conductivity of the electrolyte can be recovered. However, as far as we know, there is no relevant method until now. In this work we report a novel process, named as high temperature reduction cleaning (HTRC) process, to recover the conductivity of BZY20 from the contamination of Ni cations.

\section{Experimental}

\subsection{Material preparation}

$\mathrm{BaZr}_{0.8} \mathrm{Y}_{0.2} \mathrm{O}_{3-\delta}$ was prepared by a conventional solid state reaction method. Starting materials of $\mathrm{BaCO}_{3}$ (Wako Pure Chemical Industries, Ltd., 99.9\%), $\mathrm{ZrO}_{2}$ (Tosoh Corporation, 98.01\%), and $\mathrm{Y}_{2} \mathrm{O}_{3}$ (Shin-Etsu Chemical Co., Ltd., 99.9\%) were mixed in the desired ratio and ball-milled for $24 \mathrm{~h}$. After being 
Table 1 Conductivity of the $\mathrm{Y}$-doped $\mathrm{BaZrO}_{3}$ electrolyte layer at $600{ }^{\circ} \mathrm{C}$ in fuel cells prepared via a co-sintering process. ${ }^{8,15-24}$ The total conductivity of $\mathrm{BaZr}_{0.8} \mathrm{Y}_{0.2} \mathrm{O}_{3-\delta}$ without $\mathrm{Ni}$ contamination is higher than $10^{-2} \mathrm{~S} \mathrm{~cm}^{-1}$ at $600{ }^{\circ} \mathrm{C}$ (ref. 1,2 and 5)

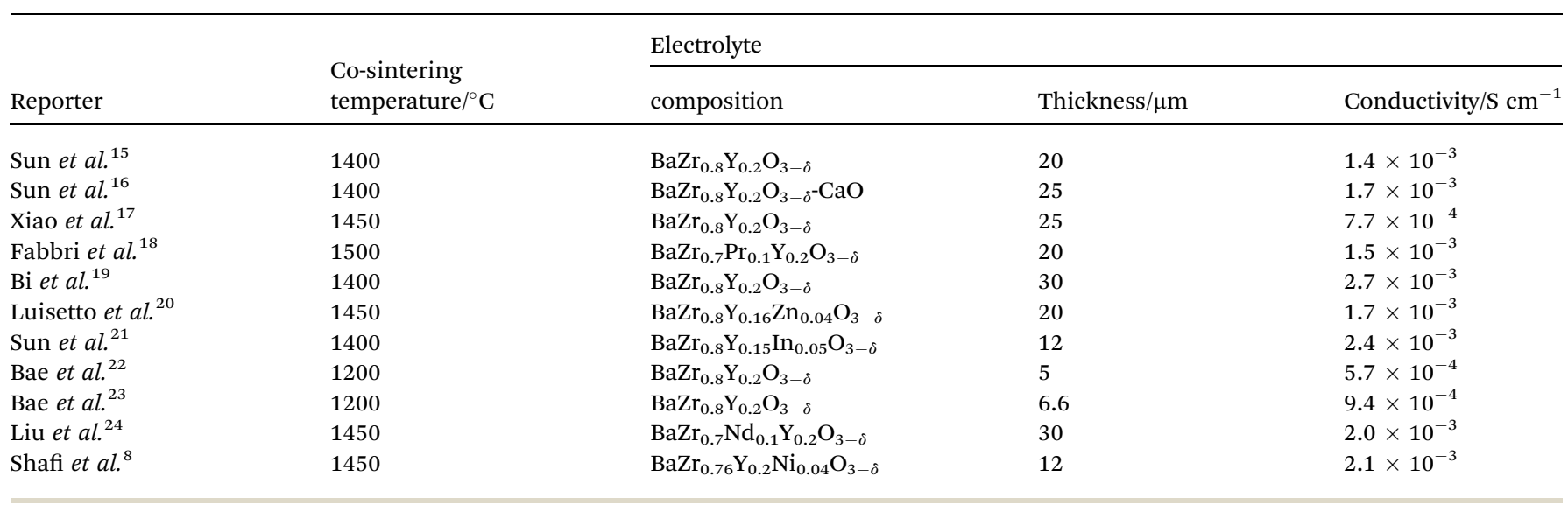
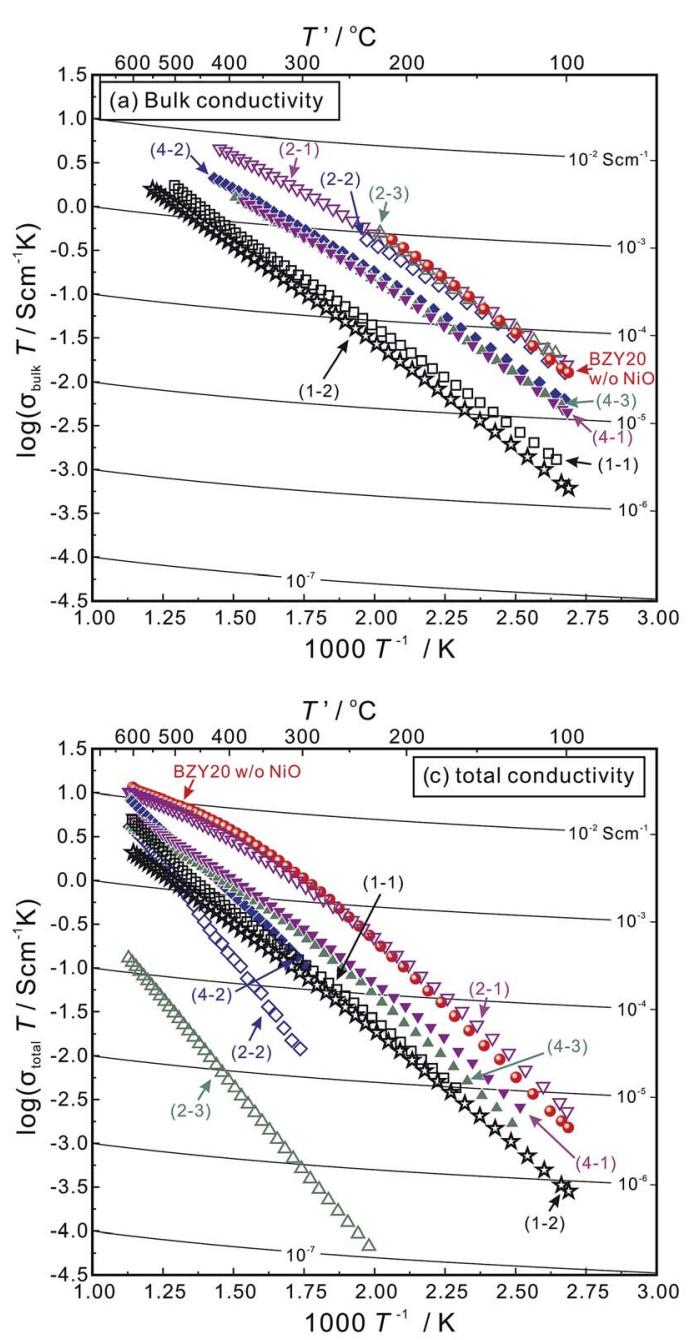

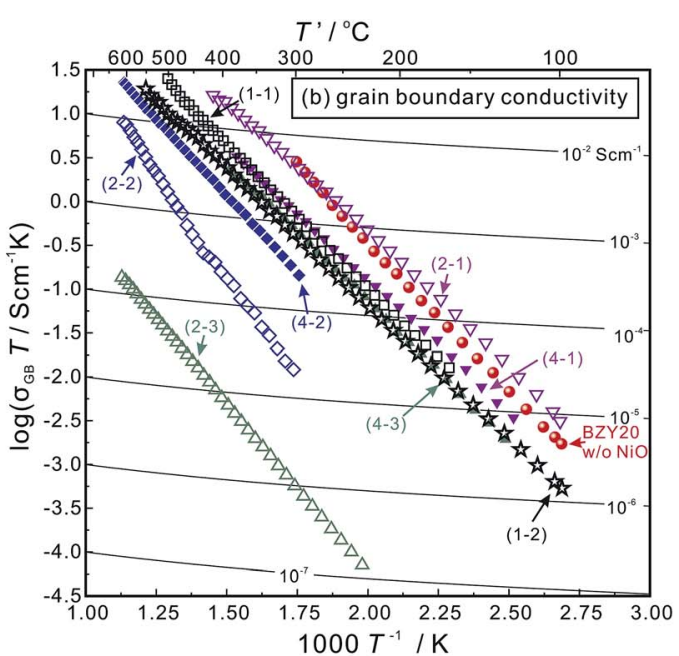

Sequence of Heat-Treatment \& Conductivity Measurements BZY2O - $5 \mathrm{NiO}$

(1) $1600{ }^{\circ} \mathrm{C}, \mathrm{O}_{2}, 24 \mathrm{~h}$ as-sintered

$\downarrow \begin{array}{ll}(1-1) \mathrm{O}_{2}-5 \% \mathrm{H}_{2} \mathrm{O} & \square \\ (1-2) \mathrm{H}_{2}-5 \% \mathrm{H}_{2} \mathrm{O} & \text { 㶦 }\end{array}$

(2) $1400{ }^{\circ} \mathrm{C}$, Ti-deoxidized $\mathrm{Ar}, 100 \mathrm{~h}$

$\downarrow \begin{array}{ll}(2-1) \mathrm{H}_{2}-5 \% \mathrm{H}_{2} \mathrm{O} & \nabla \\ (2-2) \mathrm{O}_{2}-5 \% \mathrm{H}_{2} \mathrm{O} & \diamond \\ (2-3) \mathrm{H}_{2}-5 \% \mathrm{H}_{2} \mathrm{O} & \Delta\end{array}$

(3) $600{ }^{\circ} \mathrm{C}, \mathrm{O}_{2}, 72 \mathrm{~h}$

(4) $1400^{\circ} \mathrm{C}, \mathrm{Ni}$-deoxidized $\mathrm{Ar}, 24 \mathrm{~h}$ re-sintered

$\downarrow \begin{aligned} & (4-1) \mathrm{H}_{2}-5 \% \mathrm{H}_{2} \mathrm{O} \\ & (4-2) \mathrm{O}_{2}-5 \% \mathrm{H}_{2} \mathrm{O} \\ & (4-3) \mathrm{H}_{2}-5 \% \mathrm{H}_{2} \mathrm{O}\end{aligned}$

Fig. 1 Arrhenius plots of (a) the bulk conductivity, (b) grain boundary conductivity, and (c) total conductivity of BZY20-5NiO after each step of heat-treatment. After sintering at $1600{ }^{\circ} \mathrm{C}$ in $\mathrm{O}_{2}$ for $24 \mathrm{~h}$, the conductivity was measured first in wet $\mathrm{O}_{2}$ and then in wet $\mathrm{H}_{2}$. Then, the sample was heated at $1400{ }^{\circ} \mathrm{C}$ in Ti-deoxidized Ar for $100 \mathrm{~h}$, and the conductivity was measured in wet $\mathrm{H}_{2}, \mathrm{O}_{2}$ and $\mathrm{H}_{2}$ in sequence. Finally, after the heattreatment at $600{ }^{\circ} \mathrm{C}$ in $\mathrm{O}_{2}$ for $72 \mathrm{~h}$ and subsequently at $1400^{\circ} \mathrm{C}$ in Ni-deoxidized Ar for $24 \mathrm{~h}$, the conductivity measurement was performed in wet $\mathrm{H}_{2}, \mathrm{O}_{2}$ and $\mathrm{H}_{2}$ in sequence. The conductivity of BZY2O without the NiO additive (red ball symbols) is also plotted for comparison. 
pressed into pellets under 9.8 $\mathrm{MPa}$ pressure, the sample was heat-treated at $1000{ }^{\circ} \mathrm{C}$ for $10 \mathrm{~h}$. Then, the sample was pulverized and ball-milled for $10 \mathrm{~h}$, and pressed into pellets under 9.8 MPa pressure again, with a subsequent heat-treatment at $1300{ }^{\circ} \mathrm{C}$ for $10 \mathrm{~h}$ for synthesizing. The sample was then ballmilled for $100 \mathrm{~h}$ and mixed with $\mathrm{NiO}$ powder (Nikko Rica Corporation, 99.3\%) in a molar ratio of $100: 5$ ( $~ 1.34$ wt $\%$ of $\mathrm{NiO}$, denoted as BZY20-5NiO for short). The mixture was ballmilled for $10 \mathrm{~h}$ and pressed into pellets at $392 \mathrm{MPa}$. The pelletlike samples were buried in a sacrificial powder of BZY20 $1 \mathrm{wt} \% \mathrm{BaCO}_{3}$ and heated at $1600{ }^{\circ} \mathrm{C}$ in an oxygen atmosphere for $24 \mathrm{~h}$ for sintering.

\subsection{Characterization}

The conductivities of the pellet-like samples with sputtered $\mathrm{Pt}$ electrodes were measured in a wet atmosphere of $\mathrm{O}_{2}$ or $\mathrm{H}_{2}$. Water partial pressure in these wet atmospheres was kept at 0.05 atm by bubbling through deionized water kept at $33{ }^{\circ} \mathrm{C}$. Impedance spectra were collected by A. C. impedance spectroscopy in the frequency range from $10 \mathrm{~Hz}$ to $7 \mathrm{MHz}$ using a frequency response analyzer (Solartron SI 1260, Solartron Analytical, UK) with an applied A. C. voltage of $100 \mathrm{mV}$ at temperatures ranging from 600 to $100{ }^{\circ} \mathrm{C}$.
The microstructure was observed by transmission electron microscopy (TEM) and scanning transmission electron microscopy (STEM) with a JEM-2100F (JEOL, Tokyo, Japan). Energy dispersion X-ray spectroscopy with a JED-2300 (STEM-

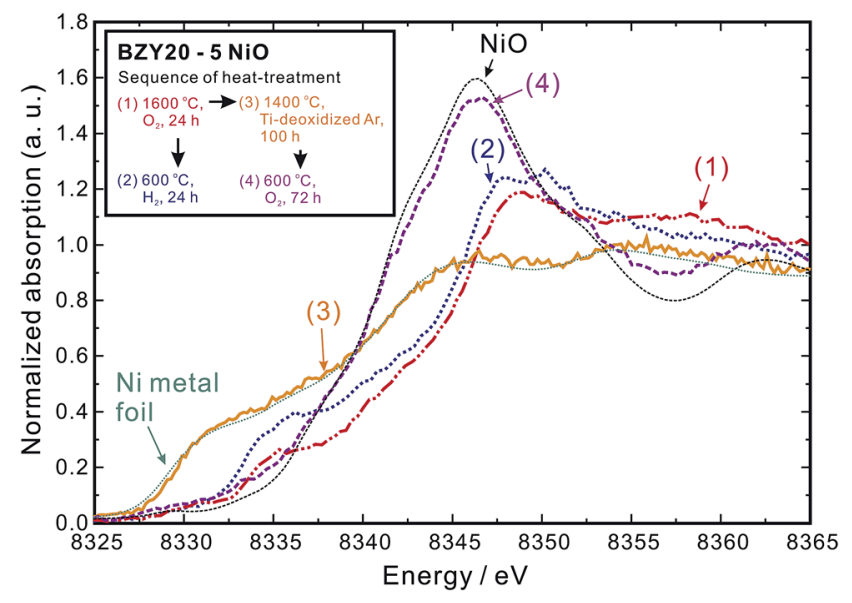

Fig. $3 \mathrm{Ni} \mathrm{K}$-edge XANES spectra of BZY20-5NiO after the heattreatments in the following sequence: (1) sintering at $1600{ }^{\circ} \mathrm{C}$ in $\mathrm{O}_{2}$ for $24 \mathrm{~h}$, followed by (2) treatment at $600^{\circ} \mathrm{C}$ in $\mathrm{H}_{2}$ for $24 \mathrm{~h}$, or (3) $1400^{\circ} \mathrm{C}$ in Ti-deoxidized Ar for $100 \mathrm{~h}$, and subsequently at (4) $600{ }^{\circ} \mathrm{C}$ in $\mathrm{O}_{2}$ for $72 \mathrm{~h}$. The spectra of $\mathrm{NiO}$ and $\mathrm{Ni}$ metal foil are shown for reference.

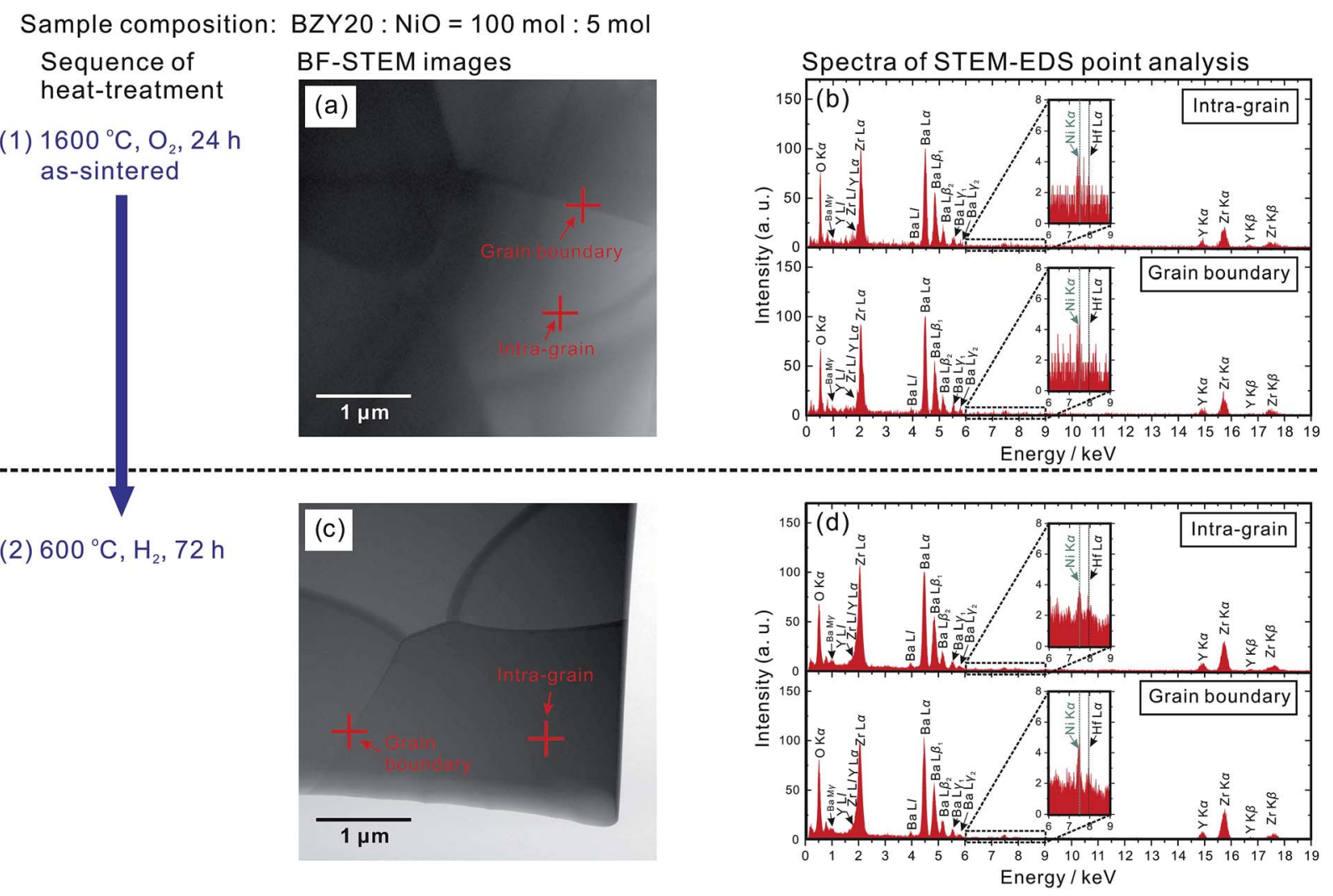

Fig. 2 Bright field STEM (BF-STEM) images of BZY2O-5NiO after (a) heating at $1600{ }^{\circ} \mathrm{C}$ in $\mathrm{O}_{2}$ for $24 \mathrm{~h}$ for sintering and (c) subsequent treatment at $600{ }^{\circ} \mathrm{C}$ in $\mathrm{H}_{2}$ for $72 \mathrm{~h}$. Cross symbols indicate locations of intra-grain and grain boundaries for STEM-EDS point analysis. Corresponding spectra given are shown in (b) and (d). A weak peak belonging to $\mathrm{Hf} L \alpha(7.90 \mathrm{keV})$ appeared close to that of $\mathrm{Ni} \mathrm{K \alpha}(7.47 \mathrm{keV})$ because the $\mathrm{ZrO} 2$ powder used in this study contained $\sim 2 \mathrm{wt} \% \mathrm{HfO}_{2}$. An unknown peak appearing around $0.78 \mathrm{keV}$ is believed to belong to $\mathrm{Ba}$ (see the ESI $\uparrow$ for details). 
EDS, JEOL, Tokyo, Japan) was used for composition measurements.

Ni K-edge X-ray absorption near-edge structure (XANES) measurements were performed at the SPring-8 synchrotron radiation facility (Hyogo, Japan) with the approval of the Japan Radiation Research Institute (JASRI) (proposal no. 2013B1568, and 2015A5330). The measurements of Ni metal foil and $\mathrm{NiO}$ were performed in the transmission mode, and the measurements of BZY20-5NiO samples were performed in the fluorescence mode by using a $\mathrm{Si}(111)$ double-crystal monochromator. The data of BZY20-5NiO samples which were sintered and subsequently heat-treated in hydrogen were collected at beamline BL14B2 at a temperature of $8 \mathrm{~K}$. The other data were collected at BL16B2 at a temperature of $20 \mathrm{~K}$.

\section{Results and discussion}

\subsection{Sintering at $1600{ }^{\circ} \mathrm{C}$}

The temperature dependence of the bulk (intra-grain), grain boundary and total conductivities of the as-sintered (at $1600{ }^{\circ} \mathrm{C}$ ) BZY20-5NiO samples in moist $\mathrm{O}_{2}$ and $\mathrm{H}_{2}$ (identified as (1-1) and (1-2), respectively) is displayed in Fig. 1. The values are lower

Sample composition: BZY20 : NiO = $100 \mathrm{~mol}: 5 \mathrm{~mol}$

Sequence of heat-treatment

(1) $1600{ }^{\circ} \mathrm{C}, \mathrm{O}_{2}, 24 \mathrm{~h}$ as-sintered

(2) $1400^{\circ} \mathrm{C}$, Ti-deoxidized $\mathrm{Ar}$, $100 \mathrm{~h}$

Ti metal was added to create extremely low $p_{\mathrm{O}_{2}}$ environment $\left(p_{\mathrm{O}_{2}} \sim 10^{-29} \mathrm{~atm}\right)$

BF-STEM images
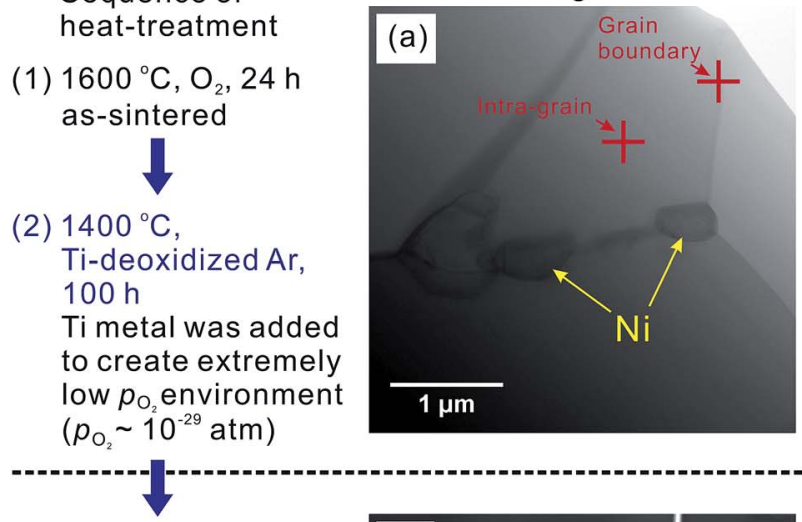

(3) $600{ }^{\circ} \mathrm{C}, \mathrm{O}_{2}, 72 \mathrm{~h}$

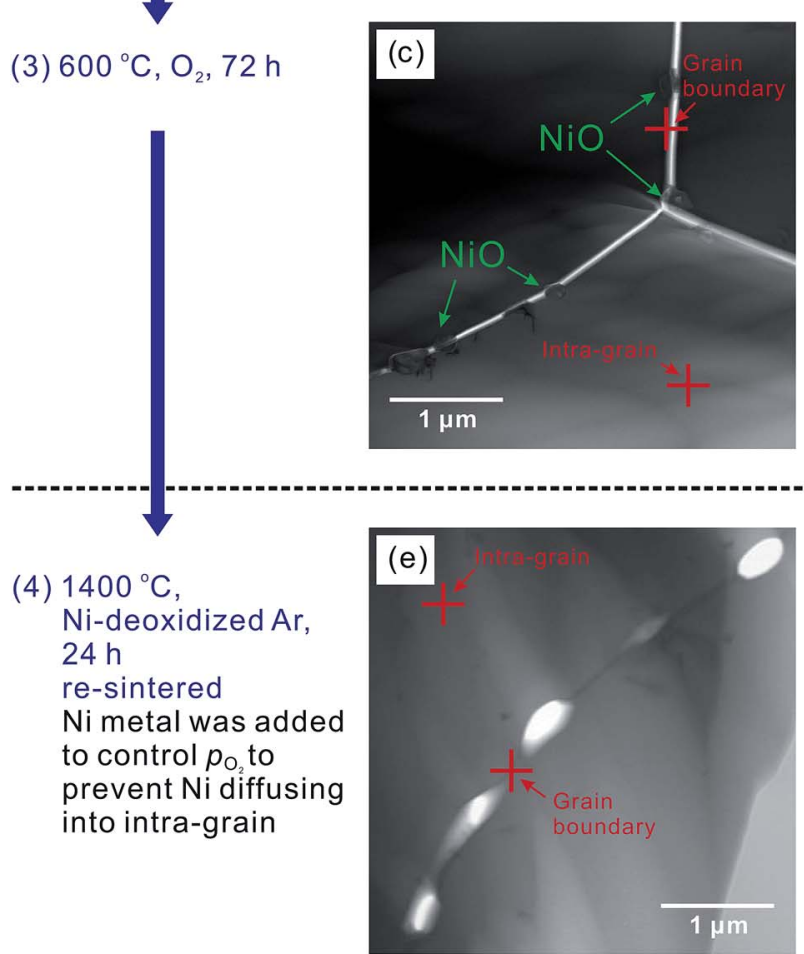

Spectra of STEM-EDS point analysis
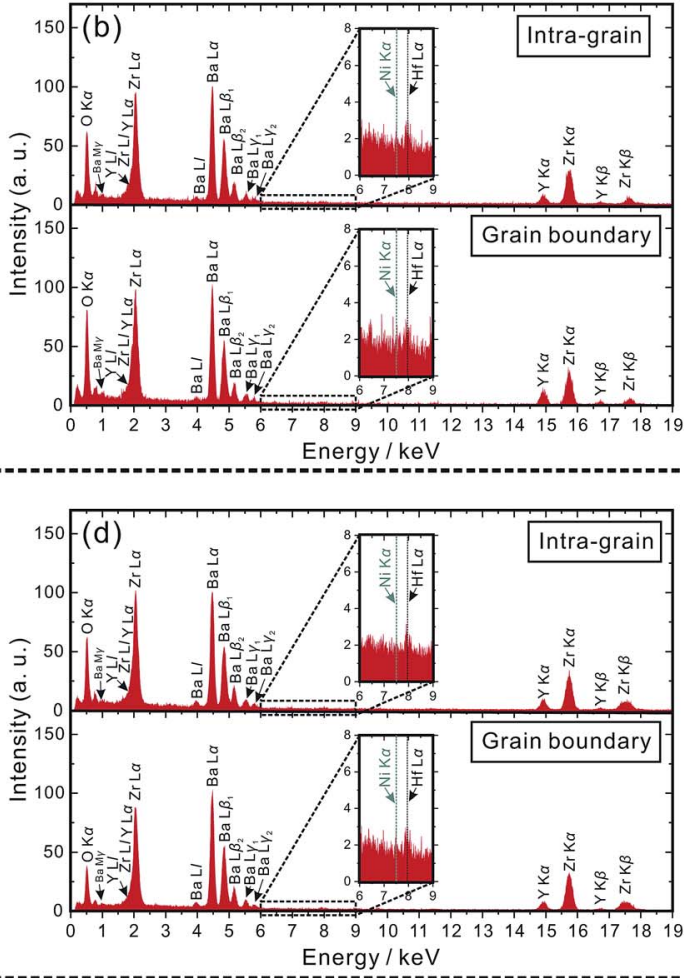

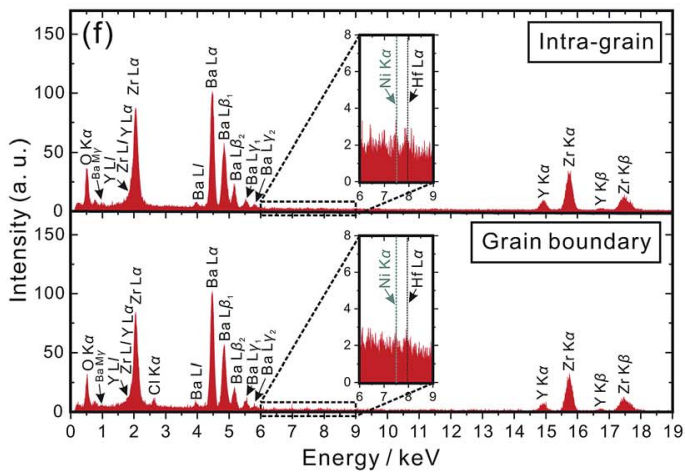

Fig. 4 BF-STEM images and spectra of STEM-EDS point analysis of the as-sintered sample of BZY20-5NiO heat-treated in sequence (a) at $1400^{\circ} \mathrm{C}$ in Ti-deoxidized Ar for $100 \mathrm{~h}$, (c) at $600^{\circ} \mathrm{C}$ in $\mathrm{O}_{2}$ for $72 \mathrm{~h}$, and (e) at $1400^{\circ} \mathrm{C}$ in Ni-deoxidized Ar for $24 \mathrm{~h}$. Cross symbols are the places for STEM-EDS analysis to determine the local composition of intra-grain and grain boundaries with the spectra given in (b), (d) and (e). A weak peak belonging to $\mathrm{Hf} \mathrm{L} \alpha(7.90 \mathrm{keV})$ appeared since the $\mathrm{ZrO}_{2}$ powder we used contains about $2 \mathrm{wt} \% \mathrm{HfO}$. A peak of $\mathrm{Cl} \mathrm{K \alpha}(2.62 \mathrm{keV})$ appeared in (f), due to the residue of bonds used for sample preparation for TEM observation. In addition, an unknown peak appeared around 0.78 keV, but is believed to belong to $\mathrm{Ba}$. 
than those of BZY20 without the NiO additive by about an order of magnitude, which is in agreement with previous reports. ${ }^{11-13}$ Probing the local composition by STEM-EDS point analysis provides confirmation of the existence of $\mathrm{Ni}$ in both the intragrain and grain boundary areas. The representative positions for analysis are marked in Fig. 2(a) along with the corresponding spectra in Fig. 2(b).

The Ni K-edge XANES spectrum of the as-sintered BZY20$5 \mathrm{NiO}$ (profile (1) in Fig. 3) is different from those of Ni metal and divalent $\mathrm{Ni}$ oxide (NiO). The Ni cations are present predominantly in the trivalent state at an interstitial position $(1 / 2,0,0)$ of the BZY20 crystal lattice. ${ }^{11}$ In our recent work, ${ }^{11}$ we demonstrated that such a specific location of Ni cations in the BZY20 lattice is the origin of the lowered conductivity of BZY20.

\subsection{Heat-treating at $600{ }^{\circ} \mathrm{C}$ in $\mathrm{H}_{2}$}

As a corollary it is very interesting and challenging to attempt conductivity recovery by excluding Ni cations from the BZY20 lattice. First, an ordinary process was attempted by exposing the as-sintered BZY20-5NiO pellet to a dry hydrogen atmosphere at $600{ }^{\circ} \mathrm{C}$. After keeping for $24 \mathrm{~h}$, the shape of the Ni K-edge XANES spectra (profile (2) in Fig. 3) did not change significantly from that of the as-sintered sample. Only a slight shift towards the lower photon energy was observed, probably due to the reduction of the NiO residue at the grain boundary. ${ }^{\mathbf{1 1}}$ The time for heat-treatment in $\mathrm{H}_{2}$ was then extended to $72 \mathrm{~h}$, but the $\mathrm{Ni} \mathrm{K}$ peak in the STEM-EDS spectra for both the intra-grain and grain boundary areas was still observed (Fig. 2(d)). These results clearly indicate that heat-treatment at a relatively lower temperature $\left(600{ }^{\circ} \mathrm{C}, \mathrm{H}_{2}\right)$ does not promote significant expulsion of $\mathrm{Ni}$ from the $\mathrm{BZY} 20$ lattice.

\subsection{Heat-treating at $1400{ }^{\circ} \mathrm{C}$ in Ti-deoxidized $\mathrm{Ar}$}

Then, the temperature was elevated to $1400{ }^{\circ} \mathrm{C}$. For safety reasons, an Ar atmosphere (containing about 0.001 vol\% $\mathrm{O}_{2}$ as-purchased) was used instead of $\mathrm{H}_{2}$. And sufficient titanium (Ti) metal was placed next to the samples (about $5 \mathrm{~mm}$ in distance) in the same furnace to control the partial pressure of oxygen at a very low level. ${ }^{29-31}$ After keeping the as-sintered BZY20-5NiO pellet in such an environment for $100 \mathrm{~h}$, it can be seen that the bulk, grain boundary and total conductivities measured in the wet $\mathrm{H}_{2}$ (plot (2-1) in Fig. 1(a)-(c)) atmosphere returned very close to the values of BZY20 without the NiO additive. The conductivity appears to have recovered after such heat-treatment in low oxygen partial pressure Ar gas. Ni K-edge XANES analysis indicates that the spectra of the sample after such heat-treatment (profile (3) in Fig. 3) almost coincide with those of the Ni metal. Furthermore, through STEM-EDS analysis, we did not detect the peak belonging to Ni in either intragrain or grain boundary area (Fig. 4(a) and (b)), but observed segregation of $\mathrm{Ni}$ metal particles at the grain boundary (Fig. 5(a)). All these results indicate that after heating at $1400{ }^{\circ} \mathrm{C}$ in Ar with very low oxygen partial pressure, $\mathrm{Ni}$ cations which had previously diffused into the BZY20 lattice segregated at the grain boundary in the form of Ni metal particles, resulting in the recovered electrical conductivity of BZY20.
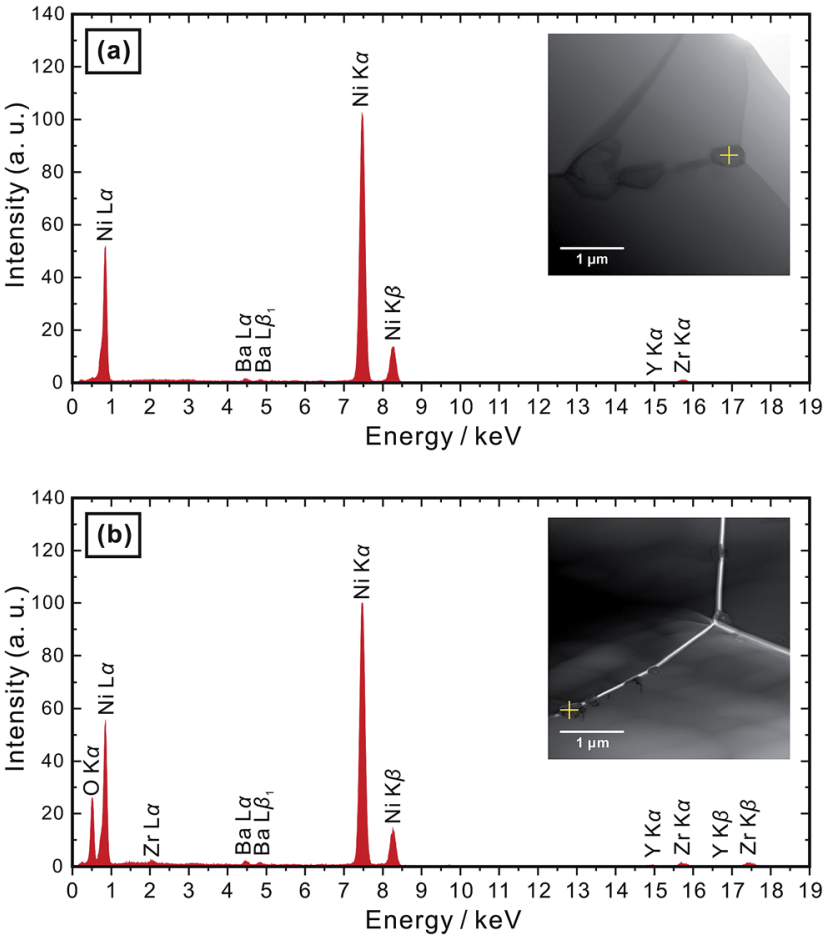

Fig. 5 STEM-EDS spectra of particles segregated at the grain boundary, which were determined to be $\mathrm{Ni}$ after the heat-treatments (a) at $1400{ }^{\circ} \mathrm{C}$ in $\mathrm{Ti}$-deoxidized $\mathrm{Ar}$ for $100 \mathrm{~h}$, and $\mathrm{NiO}$ after subsequent treatment (b) at $600{ }^{\circ} \mathrm{C}$ in $\mathrm{O}_{2}$ for $72 \mathrm{~h}$. Cross symbols in the BF-STEM images shown in insets indicate the locations of STEM-EDS point analysis.

\subsection{Delamination of grain boundary by exposing to $\mathrm{O}_{2}$}

However, further experimentation indicated some additional issues. After the conductivity measurement in wet $\mathrm{H}_{2}$, we altered the atmosphere to wet $\mathrm{O}_{2}$. Although the bulk conductivity remained almost unchanged, the grain boundary conductivity decreased dramatically (plot (2-2) in Fig. 1(b)). The atmosphere was then altered to wet $\mathrm{H}_{2}$ again, and a further drop of the grain boundary conductivity (plot (2-3) in Fig. 1(b)) occurred.

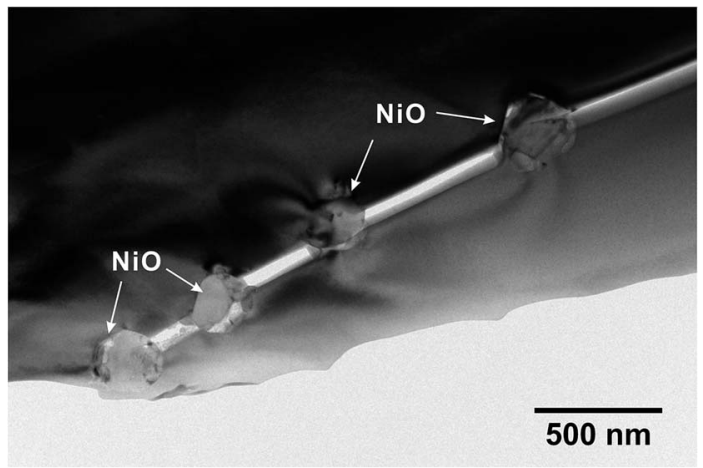

Fig. 6 A TEM image of $\mathrm{BZY} 20-5 \mathrm{NiO}$ heat-treated at $600{ }^{\circ} \mathrm{C}$ in $\mathrm{O}_{2}$ for $72 \mathrm{~h}$. Before this heat-treatment, the sample was sintered at $1600^{\circ} \mathrm{C}$ in $\mathrm{O}_{2}$ for $24 \mathrm{~h}$ and then subjected to reduction heat-treatment at $1400^{\circ} \mathrm{C}$ in Ti-deoxidized Ar for $100 \mathrm{~h}$. 
In order to clarify the reason, the BZY20-5NiO sample after keeping at $1400{ }^{\circ} \mathrm{C}$ in Ti-deoxidized Ar for $100 \mathrm{~h}$ was then exposed to $\mathrm{O}_{2}$ at $600{ }^{\circ} \mathrm{C}$ for $72 \mathrm{~h}$. XANES analysis (profile (4) in Fig. 3) indicated that the oxidation state of $\mathrm{Ni}$ in such a sample is very close to that in divalent $\mathrm{Ni}$ oxide (NiO). The microstructure observation (Fig. 4(c) and 6) showed delamination along the grain boundaries in the sample which was exposed to the oxygen atmosphere after the heat-treatment at $1400{ }^{\circ} \mathrm{C}$ in Ti-deoxidized Ar for 100 h. And as can be clearly seen in Fig. 6, adjacent BZY20 grains were only connected by $\mathrm{NiO}$ particles (STEM-EDS point analysis results of these NiO particles are given in Fig. 5(b)). The reason for such a phenomenon can be explained with a schematic displayed in Fig. 7. Since the molar volume of $\mathrm{NiO}$ at room temperature $\left(11.20 \mathrm{~cm}^{3} \mathrm{~mol}^{-1}\right)$ is larger than that of $\mathrm{Ni}\left(6.59 \mathrm{~cm}^{3} \mathrm{~mol}^{-1}\right)$, strains generated due to the oxidation of $\mathrm{Ni}$ to $\mathrm{NiO}$ particles caused delamination along the grain boundaries (Fig. 7(c)), resulting in a great decrease in the grain boundary conductivity. When the sample was exposed to the hydrogen atmosphere again, some of the grains which were used to be connected by $\mathrm{NiO}$ particles became disconnected due to the reduction of NiO to smaller Ni particles (Fig. 7(f)). And the grain boundary conductivity further decreased.

\subsection{Sequential processes to eliminate delamination along grain boundaries}

Such delamination of grain boundaries will be problematic, since the cathode side of the electrolyte is exposed to $\mathrm{O}_{2}$ during the fuel cell operation. To solve this problem, a series of sequential processes were designed. The sample which was heated at $1400{ }^{\circ} \mathrm{C}$ in the Ti-deoxidized $\mathrm{Ar}$ atmosphere for $100 \mathrm{~h}$ (Fig. 7(b)) was first kept at $600{ }^{\circ} \mathrm{C}$ in $\mathrm{O}_{2}$ for $72 \mathrm{~h}$ to deliberately introduce delamination along the grain boundaries (Fig. 7(c)). Subsequently, the sample was re-sintered at $1400{ }^{\circ} \mathrm{C}$ in an $\mathrm{Ar}$ atmosphere for $24 \mathrm{~h}$ to re-connect the grain boundary with embedded NiO particles (Fig. 7(d)). When this sample was further exposed to a reducing atmosphere, there was no risk of grain boundary delamination, since the embedded NiO particles were reduced to smaller Ni particles (Fig. 7(e)). A key point that must be emphasized here is that during the re-sintering step, it was vital to protect $\mathrm{NiO}$ from reduction to $\mathrm{Ni}$ and also avoid Ni cations diffusing into the BZY20 lattice again. Hence, $\mathrm{Ni}$ metal was placed next to the samples (about $5 \mathrm{~mm}$ in distance) to control the oxygen partial pressure in the $\mathrm{Ar}$ atmosphere. The oxygen partial pressure corresponding to the equilibrium, $2 \mathrm{Ni}+\mathrm{O}_{2}=2 \mathrm{NiO}$, may not be sufficient to further oxidize divalent $\mathrm{Ni}$ cations to trivalent ones, which is a necessary condition for Ni cations to diffuse into the BZY20 lattice. ${ }^{\mathbf{1 1}}$ Such a re-sintering strategy appeared to be effective since a partially re-connected grain boundary was observed (Fig. 4(e)). However, a very small peak (close to the noise level) belonging to $\mathrm{Ni} \mathrm{K}$ appeared in the STEM-EDS spectra of the intra-grain area, as shown in Fig. 4(f). This result indicated that a very small amount of $\mathrm{Ni}$ cations, diffused back into the BZY20 lattice during the re-sintering process. As a consequence, the bulk conductivity (plots (4-1), (4-2) and (4-3) in Fig. 1(a)) is smaller than that of BZY20 without the NiO additive, but obviously higher than the as-sintered BZY20-5NiO sample. It is worth noting that the grain boundary and total conductivities were relatively stable with the atmosphere altering between wet $\mathrm{H}_{2}$ and wet $\mathrm{O}_{2}$. And the total conductivity of profiles (4-1) and (4-3) is obviously higher than that of the as-sintered BZY20-5NiO in wet $\mathrm{H}_{2}$ (plot (1-2) in Fig. 1(c)).

Schematic of High Temperature Reduction Cleaning (HTRC) Process

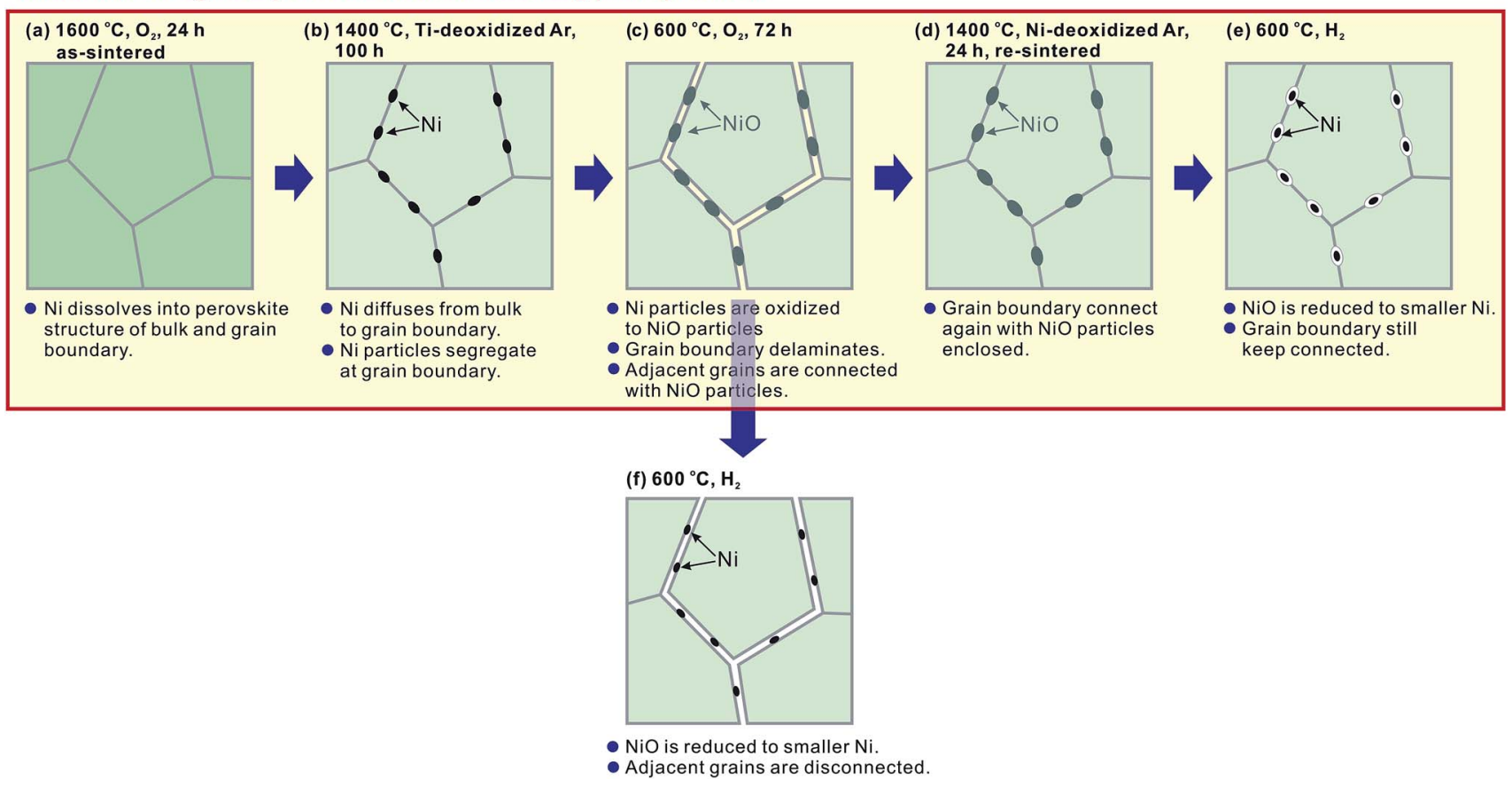

Fig. 7 A schematic illustration of microstructural changes during the high temperature reduction cleaning (HTRC) process. 


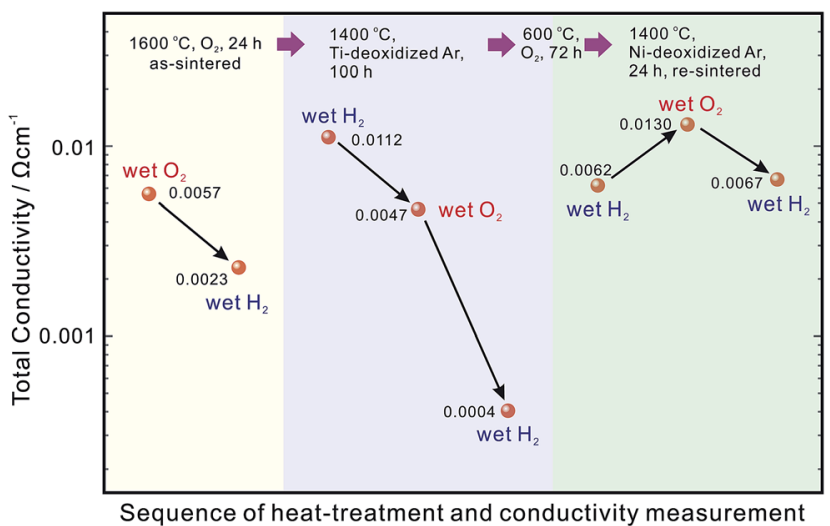

Fig. 8 Variation of total conductivity at $600^{\circ} \mathrm{C}$ in different treatment scenarios. The sample after the final re-sintering process at $1400^{\circ} \mathrm{C}$ in $\mathrm{Ni}$-deoxidized Ar for $24 \mathrm{~h}$ exhibits a higher total conductivity at $600^{\circ} \mathrm{C}$ in wet $\mathrm{O}_{2}$ than that in wet $\mathrm{H}_{2}$, due to the generation of hole conduction in the oxidizing atmosphere.

A summary of the total conductivity at $600{ }^{\circ} \mathrm{C}$ of BZY20$5 \mathrm{NiO}$ after different heat-treatment scenarios is displayed in Fig. 8. The value after the high temperature reduction cleaning (HTRC) process in wet $\mathrm{H}_{2}\left(0.0062\right.$ and $\left.0.0067 \mathrm{~S} \mathrm{~cm}^{-1}\right)$ is about three times larger than that of the as-sintered sample $(0.0023 \mathrm{~S}$ $\mathrm{cm}^{-1}$ ). Although a more tailored control of the oxygen partial pressure in the atmosphere during the re-sintering step needs further attention, it is clear that the HTRC process demonstrated in this work is very effective for the recovery of the electrical conductivity of electrolytes contaminated by impurity cations.

\section{Conclusion}

A novel high temperature reduction cleaning process was demonstrated in this work to recover the electrical conductivity of NiO-contaminated Y-doped $\mathrm{BaZrO}_{3}$. Ni cations diffused into the BZY lattice were observed to be expulsed and segregated at the grain boundary in the form of Ni metal particles after heating at $1400{ }^{\circ} \mathrm{C}$ in a Ti-deoxidized $\mathrm{Ar}$ atmosphere. As a consequence, the conductivity of BZY returned to the value of those without being contaminated by NiO. However, the segregated $\mathrm{Ni}$ particles induced delamination along the grain boundary when they are oxidized to the NiO particles, and a series of sequential heattreatments in the atmosphere with carefully controlled partial pressure of oxygen were designed to effectively solve such a problem.

\section{Acknowledgements}

This work was supported by Grant-in-Aid for Scientific Research A (Grant No. 15H02311) from the Japan Society for the Promotion of Science (JSPS). The authors thank Prof. K. T. Jacob at Indian Institute of Science for valuable comments and Dr Susumu Tsukimoto at Tohoku University for STEM-EDS analysis.

\section{References}

1 Y. Yamazaki, R. Hernandez-Sanchez and S. M. Haile, Chem. Mater., 2009, 21, 2755.

2 D. Pergolesi, E. Fabbri, A. D'Epifanio, E. D. Bartolomeo, A. Tebano, S. Sanna, S. Licoccia, G. Balestrino and E. Traversa, Nat. Mater., 2010, 9, 846.

3 D. Han, Y. Nose, K. Shinoda and T. Uda, Solid State Ionics, 2012, 213, 2.

4 D. Han, K. Shinoda, S. Sato, M. Majima and T. Uda, J. Mater. Chem. A, 2015, 3, 1243.

5 D. Han, N. Hatada and T. Uda, J. Am. Ceram. Soc., 2016, DOI: 10.1111/jace.14377.

6 K. Katahira, Y. Kohchi, T. Shimura and H. Iwahara, Solid State Ionics, 2000, 138, 91.

7 Y. Guo, Y. Lin, H. Shi, R. Ran and Z. Shao, Chin. J. Catal., 2009, 30, 479.

8 S. P. Shafi, L. Bi, S. Boulfrad and E. Traversa, J. Electrochem. Soc., 2015, 162, F1498.

9 C. Duan, J. Tong, M. Shang, S. Nikodemski, M. Sanders, S. Ricote, A. Almansoori and R. O'Hayre, Science, 2015, 349, 1321.

10 S. Robinson, A. Manerbino, W. Grover Coors and N. P. Sullivan, Fuel Cells, 2013, 4, 584.

11 D. Han, K. Shinoda, S. Tsukimoto, H. Takeuchi, C. Hiraiwa, M. Majima and T. Uda, J. Mater. Chem. A, 2014, 2, 12552.

12 C. Y. Yoo, D. S. Yun, J. H. Joo and J. H. Yu, J. Alloys Compd., 2015, 621, 263.

13 E. Kim, Y. Yamazaki, S. M. Haile and H. I. Yoo, Solid State Ionics, 2015, 275, 23.

14 D. Han, Y. Otani, Y. Noda, T. Onishi, M. Majima and T. Uda, RSC Adv., 2016, 6, 19288.

15 W. Sun, L. Yan, Z. Shi, Z. Zhu and W. Liu, J. Power Sources, 2010, 195, 4727.

16 Z. Sun, E. Fabbri, L. Bi and E. Traversa, J. Am. Ceram. Soc., 2012, 95, 627.

17 J. Xiao, W. Sun, Z. Zhu, Z. Tao and W. Liu, Mater. Lett., 2012, 73, 198.

18 E. Fabbri, L. Bi, H. Tanaka, D. Pergolesi and E. Traversa, Adv. Funct. Mater., 2011, 21, 158.

19 L. Bi, E. Fabbri, Z. Sun and E. Traversa, Energy Environ. Sci., 2011, 4, 1352.

20 I. Luisetto, S. Licoccia, A. D'Epifanio, A. Sanson, E. Mercadelli and E. D. Bartolomeo, J. Power Sources, 2012, 220, 280.

21 W. Sun, Z. Shi, M. Liu, L. Bi and W. Liu, Adv. Funct. Mater., 2014, 24, 5695.

22 H. Bae, J. Choi, K. Kim, D. Park and G. Choi, Int. J. Hydrogen Energy, 2015, 40, 2775.

23 H. Bae and G. Choi, J. Power Sources, 2015, 285, 431.

24 Y. Liu, Y. Guo, R. Ran and Z. Shao, J. Membr. Sci., 2012, 415416, 391.

25 J. M. Polfus, M. Fontaine, A. Thøgersen, M. Riktor, T. Norby and R. Bredesen, J. Mater. Chem. A, 2016, 4, 8105.

26 J. Tong, D. Clark, L. Bernau, M. Sanders and R. O'Hayre, J. Mater. Chem., 2010, 20, 6333. 
27 J. Tong, D. Clark, M. Hoban and R. O'Hayre, Solid State Ionics, 2010, 181, 496.

28 S. Nikodemski, J. Tong and R. O'Hayre, Solid State Ionics, 2013, 253, 201.

29 R. Akila, K. T. Jacob and A. K. Shukla, Bull. Mater. Sci., 1986, 8, 453.
30 T. H. Okabe, R. O. Suzuki, T. O. Oishi and K. Ono, Mater. Trans. JIM, 1991, 32, 485.

31 Z. Cao, W. Xie, I. Jung, G. Du and Z. Qiao, Metall. Mater. Trans. B, 2015, 46, 1782. 